\title{
A Groupware-based Peer Review Process: An Exploratory Case Study
}

\author{
Bridget N. O'Connor \\ New York University \\ bridget.oconnor@nyu.edu
}

\begin{abstract}
This paper uses Lewin's planned change theory and Rogers' diffusion of innovation theory as lenses through which to describe what occurred in an organizationally flat, team-based organization when it rolled out a groupware-based peer review process. The Information Systems Department wanted to implement a high-level groupware product. The Human Resource Department wanted to enable team members to rate each other on their teambuilding skills as well as provide a criterion to be used by the organization's Policy Committee in awarding biannual bonuses. Literature related to corporate peer reviews as well as the use of groupware provided the basis for questions posed. Both nondirective and focused interviews were conducted with key players and a sampling of actual evaluation data was collected. Analysis indicated that perceived management (non)commitment to using peer review data and issues of confidentiality may have led many individuals to be skeptical about the value of a peer review. As to the use of groupware to enable the evaluation, users were quite pleased; however, planners' initial resistance to using this technology was evident and early efforts to devise usable reports were troublesome.
\end{abstract}

Keywords: groupware, peer review, planned change, innovation

\section{Background to the Problem}

The ability to work effectively as a member of a team is a vital skill in most organizations. Teams have been described as the basic business unit of the global economy and teamwork as "the final ingredient that makes all the other parts add up to something greater than the sum of their parts" (O'Hara-Devereaux \& Johansen 1994, pp. 138-139). Teams have advantages over traditional hierarchical organizational structures as teams can be flexible and respond creatively and quickly to changing economic and social forces. Effective teamwork mandates that individuals have a wide range of communication skills and styles, including the ability to give and take frank criticism, provide selfexamination of team effectiveness, and accept shared responsibility for outcomes (Weisbord, 1987).

As teamwork becomes more and more the norm for the way work is done, the issue of compensating individual team members for group productivity becomes apparent. Compensation is more than just salary--it tells us how well we are doing; it tells us the value of our work within the larger organization; and it tells us our value as compared to our fellow workers. In most organizations, compensation figures are computed based on set salaries or hourly wages. In-

Material published as part of this journal, either on-line or in print, is copyrighted by the publisher of Informing Science. Permission to make digital or paper copy of part or all of these works for personal or classroom use is granted without fee provided that the copies are not made or distributed for profit or commercial advantage AND that copies 1) bear this notice in full and 2) give the full citation on the first page. It is permissible to abstract these works so long as credit is given. To copy in all other cases or to republish or to post on a server or to redistribute to lists requires specific permission and payment of a fee. Contact Editor@gise.org to request redistribution permission. creasingly, however, organizations are experimenting with systems whereby employees are rewarded for extraordinary efforts (Flynn, 1994; Work week: Evaluations, 1995). The resulting problem is how to allocate reward dollars to individuals for team outcomes.

As a potential response to this problem, some corporations are adopting aspects of university faculty peer review systems. In university merit/performance systems, the basic premise is that members of an academic community are able to give honest, evaluative, and constructive feedback to each other. Peer review appears to work in academe, if no other reason than historically, "it's the way we have always done it."

Several distinctions complicate corporate peer evaluation efforts, however. One primary problem has been identifying and measuring specific performance outcomes for diverse job categories.

Effective work teams are often made up of individuals who have a wide range of content expertise and come from differing organizational levels; teams are often not truly "peer." The second problem has been behavioral, how to get the workforce itself to accept changes in the way its compensation figures are determined.

Additionally, since teams may exist for short periods of time or be ongoing; how often should reviews be done? In a given group, particularly a virtual group, an individual may have more--or less--responsibility than others; should criteria differ? Problems can also arise as the very concept of peer evaluation differs from most existing corporate evaluation norms and individuals $=$ experiences with how evaluation should take place. These problems compound when a flat organization rewards team efforts rather than individual efforts. Even when concrete team outcomes are 


\section{Groupware-based Peer Review Process}

measurable, the question is how to recognize and compensate a specific individual for his or her contribution to a final product.

Team peer evaluations also add new layers of administrative issues for human resource professionals. Even if everyone understands and buys into the peer evaluation process, it is difficult to ensure the compilation of anonymous data in a timely manner and in an appropriate format for those who will use it. This is why groupware was considered to be a potential enabler of the peer review process, as it supports group processes and productivity (as opposed to individual productivity). Often called group support systems (GSS) or electronic meeting systems, groupware products are evolving.

Level 1groupware products include screen sharing capabilities and electronic mail. Level 2 groupware products are virtual toolboxes of support for group processes such as group writing, idea organizing, and voting. Level 2 products can perform data manipulation and statistical analysis as well as provide hardcopy printouts of exact textual discussions (Vogel, 1990). Level 3 systems, currently under development, include filtering systems, agents, and tools such as Roberts Rules of Order (Hsu, 1993).

\section{An Exploratory Case Study}

This paper demonstrates how an information systems director, a human resource executive, and a corporate trainer worked together to design and implement a technologysupported peer review system and the results of that effort. This is an exploratory case study showing how two innovations--a peer review process and a Level 2 groupware product--were rolled out together as a means to enable the peer review process to happen easily, anonymously, and efficiently. The specific groupware used was GroupSystems for Windows TM, which allowed peer groups to complete reviews at their own time and in their own offices (different time/different place). The statistical reports generated through the system were expected to provide useful performance data quickly.

Individual team members rated and described each other's contributions to a team's performance, and these ratings were to be used to provide feedback to individuals on their teambuilding skills as well as serve as one criterion for Policy Committee members who were awarding biannual bonuses. While peer review had no history in this organization, a bonus system was already in place as an established compensation method. Moreover, for most users, this was their first experience using a Level 2 groupware product.

\section{Prior Research}

Evidence exists that team-based peer review procedures are being implemented in organizations; however, the findings are mixed. In a survey investigating self-directed teams, Hitchcock (1996) found that linking peer reviews to merit pay was not well received. However, peer reviews were more accepted in field studies where it was reported that management had clearly identified team priorities, results, and appropriate measures (Talbott, 1994; Zigon, 1997). It is clear that organizations are working to develop measures of team performance, citing the need for the soft skills required for effective teamwork (Covey, 1996). Peer reviews have been described as a way for teams to support each other in improving both individual and organizational performance ("The Power of Peer Review," 1994).

Studies related to the use of information technology have shown that groupware can support data collection, processing, and distribution. Groups using technology work longer (Steeb \& Johnston, 1981; Gallupe \& McKeen, 1990; Caouette \& O'Connor, 1998) and have higher quality outcomes on certain tasks, such as idea generation (Valacich, in press). Longitudinal research suggests this can be heightened over time (Hackman, 1991; Martz, Vogel, \& Nunamaker, 1992). Other studies, however, have shown that some users do not like using the computer, depending upon their own expectations, previously existing organizational norms, and/or their own experiences in using the groupware previously ( $\mathrm{O}=$ Connor $\&$ Bronner, 1995). As groupware has been implemented, the tools have been adapted to the context and the priority of the task (Bikson \& Eveland, 1996). In an investigation of a Level 1 system, team members using groupware reported more confidence in their outcomes (McClernon \& Swanson, 1995). Increased information handling also raises questions regarding who has access to information and additional questions related to problems of misinterpreting information (Smith \& Vanecek, 1990).

This case research was guided by the following questions:

What formal and informal activities related to the rollout of the technology-based peer review process took place?

What were individual reactions to the peer review process?

What impact (if any) did the use of the technology have on the overall value of the peer review process?

\section{The Research Method}

This corporation was a specialized financial-guarantee insurance company based in New York City where deals were the basis for a project director assigning the right mix of individuals to work together. Rarely did the exact same team work on a given deal and deals could take as little as two hours or as long as six months to complete. The corporation also had a history of using computers in all phases of their day-to-day work and some individuals had had some experiences using an earlier version of the groupware, GroupSystems V. Because it was organizationally flat, this medium-sized corporation provided a useful backdrop for an investigation of peer review and groupware as teamwork 
was the primary form of decision making and all employees were technologically adept.

The case study has been called the most famous (or infamous) methodology in business education (Gay \& Diehl, 1992). As a research method, case study has a history of being used successfully in investigating human resource development in small to medium sized companies (Rowden, 1995). A case study allows many variables to be examined at the same time in a real-world context. While insights garnered from case study research lack generalizability, they do provide insights as to what happened and why when investigating a new phenomenon (Gay \& Diehl, 1992). The case discussed here can be labeled "partnership research." In partnership research, the research problem is derived from practice, but both partners anticipate using the results of the research for different purposes (McLean, 1995); the organization to improve practice and in this instance, the researcher to improve education.

\section{Data Collection and Analysis}

To determine the value of the peer review process from management's viewpoint, I conducted nondirective (unstructured), face-to-face interviews with the chief executive officer, the information systems director, the human resource executive, and the corporate trainer at all stages of the process. The nondirective interview is flexible and because as the interviewer does not provide direction, respondents "can be encouraged to relate their experiences, describe whatever events seem real to them, provide their own definitions of the situations, and to reveal their opinions and attitudes as they see fit" (Frankfort-Nachmias \& Nachmias, 1996, p. 235). Nondirective interviews were considered an appropriate data collection method because the topic of a technologysupported peer review could be perceived as complex and emotionally loaded (Merriam and Simpson, 1995). Nondirective interview data can provide insights not only on what happened, but how and why and from various perspectives.

To see first-hand how the peer review instrument was used, I reviewed (anonymously) responses to the peer review instrument. Additionally, focused (structured) telephone interviews were held with four participating individuals who volunteered to discuss their experiences. While the focused interview is the least flexible of interviews, its use reduced the risk that the order and the wording of questions would influence responses (Frankfort-Nachmias \& Nachmias, 1996). The interview guide was divided into two parts, one evaluating the peer review process itself and the other the use of the groupware (see Appendix A). All interviewees were assured of complete confidentiality; I would be the only person to have access to the interview data or to know who had been interviewed. The focused telephone inter- views, which ranged in length from 20 minutes to 55 minutes, were tape recorded and subsequently transcribed. Data were analyzed by examining recurring themes and triangulating findings to ensure reliability.

\section{The Peer Review Process}

Results The introduction section of the peer review questionnaire that I had drafted set out objectives and guidelines (see Appendix B). The peer review questions themselves were based on the ten attributes of effective team work: commitment, acceptance, clarification, belonging, involvement, support, achievement, pride, recognition, and satisfaction (Kormanski \& Mozenter, 1987). Specific attributes were described relative to the work being done, and required respondents to rate each of his or her team members on a five-point Likert scale and to offer a critical incident as evidence of the rating. For example, an item measuring support read:

$\mathrm{He} /$ she has good communication skills; motivates the team; serves as a role model; takes time to mentor/coach; provides timely feedback; is approachable; demonstrates sensitivity; does not favor one team member over another. Rating:

\section{Critical Incident:}

Much thought and discussion went into the final decision to have raters electronically sign their evaluation reports. Because it was deemed important to have some level of accountability, raters were asked to add their names to their evaluations. Reviewers were promised that they would only be connected with a specific review should it be apparent that a review was not given seriously or was extraordinarily negative. Additionally, individuals were repeatedly assured that no one other than the human resource executive who was compiling the data could know specifically who had said what about whom, and this information would not be readily available as the sign "sheet" was only linked to the reviews and not automatically available.

Team members had access to the software and the evaluation files via a local area network that connected their office computers to a central file server. Within the groupware, the information systems director had established an electronic folder for each of four specific deals (projects), and the twenty individual reviewers had access to only those folders for which he or she was a deal participant. Signing on required users to click on the Agenda icon, and then identify a specific deal. At that point, eligible reviewers were automatically ushered into the vote tool, where they were asked to "click" the name of the individual they were rating, then rate the individual as described earlier. Changes could be made on evaluations up to the point when the ballot was cast.

Compiled results would be available to the human resource executive, who would compile ratings on individuals and forward 


\section{Groupware-based Peer Review Process}

the ratings to the individual's manager and the organization's 12-member Policy Committee. Managers could share results with the individual being rated and the Policy Committee would have an additional criterion for the biannual bonus discussion process.

\section{Results}

The work of both Everett Rogers and Kurt Lewin provided the lens for examining this case. Everett Rogers explained that characteristics of an innovation influence its infusion. Rogers explained that the rate of adoption differs depending on five characteristics: relative advantage, compatibility, complexity, trialability, and observability (Rogers, 1983). This study involved the infusion of two innovations simultaneously, and these terms can help us understand the innovations' acceptance. As a means to put the case in perspective, Kurt Lewin's planned change model calls for continual progression through three stages: (1) unfreezing; (2) changing (or moving); and (3) refreezing. (Lewin, 1972) Unfreezing is the stage where individuals become aware of the innovation; changing involves actually using the innovation; and refreezing, a determinant of an innovation's acceptance, is where the innovation becomes "the way we do things around here." These concepts will be used to describe what happened in this case and why.

What formal and informal activities related to the rollout of the technology-based peer review process took place?

Unfreezing Stage. Training played a crucial role in the unfreezing stage. An informational meeting was held to describe the organization's rationale for implementing a peer review, as well as provide guidelines for how to provide constructive feedback. The procedures for the process were outlined and an opportunity for questions and discussion was provided. A week or so later, individuals were trained to use the software.

Changing Stage. Upon the completion of each of four deals, the twenty participants in those deals were asked to complete the peer review instrument. The human resource executive, the information systems manager, and the corporate trainer were all available for questions and support throughout. These planners reported that users reported problems with the system and with a too-lengthy questionnaire. To address these concerns, procedures were changed mid-course to allow individuals to select only two or three colleagues to rate per deal, and not require responses to every question.

Planners also found that numerical ratings were often not consistent with the critical event described. Despite initial training, describing critical events turned out to be a challenge for most respondents. Several individuals, however, were quite adept and at ease with the process; examples of appropriate critical events follow:

He has done a good job of assessing some of the underlying operational and credit issues and working through the details to make sure the transaction mechanics are properly structured.

Communications in the form of email status updates are a key strength. He has also done an excellent job of alerting team members and management of potential problems and delays in arranging liquidity.

She has very good judgment skills and knows when to stand firm and when to give in when negotiating this deal. She was able to develop a model to present value the arbitrage amount so we would know how much to take as an upfront fee. We were able to get an additional $\$ 500,000$ in fees this year.

However, much of the resultant data was often vague or incomplete. The following critical incidents demonstrate these problems:

The best person to work with in this company!

He tends to employ his knowledge of the industry as it pertains to his area of expertise in a "take it or leave it" manner rather than trying to work with the team to achieve results.

She was good at keeping the customer happy and addressing customer concerns.

He definitely counts on others to do his work. He will generally take on the easiest components of the transaction, not caring much for the "details" such as legal documentation or other intricacies (mechanics) of the transaction. He is very quick, however, to opine in front of senior management, so that they have the impression he has done all the work.

What were individuals' reactions to the peer review process?

Overall, while it had been anticipated that team members would easily find words to describe each other's performance, many had difficulty in doing so. While it had been anticipated that completing reviews would take only a few minutes each, individuals reported spending up to an hour or two on a single review. While it had been anticipated that the initial training on understanding the purpose of the reviews and completing reviews would be adequate, it was not.

Consistent with the work of Talbott (1994) and Zigon (1997), priorities, results and proper measures were important as several of those interviewed reported that they understood an official and an unofficial reason for the peer reviews. Nearly all of the individuals interviewed reported they had never had any feedback: "I never knew what the results were or where they [reviews] went or how they were tabulated or what feedback was given." This particular interviewee related his lack of feedback to the unofficial reason that data were needed to deal with two individuals known to be non-performers and who were consequently moved to other 
positions. The individual who did report getting feedback did not feel that data were used by top management as intended: "Eventually, yeah, I did get feedback. It [feedback] was very good and you know, that is why I say that it is all a political game here because despite the fact that I was ranked high in the company, I was passed over for promotion. ... Yes, I think it [the peer review process] is important, and it also needs to be treated importantly as well by senior management." Later in the interview, she said: "Where the peer review process was meant to work was for those people who were most at risk from suffering from it."

The peer review instrument itself, likewise, met with mixed reactions; one comment was "[I] worked in a very small (at that time) group of people so you really knew the players pretty well which is why it [the instrument] was easy to use, and I felt comfortable using it." Another interviewee reported that "If someone gets all good [response], they are good. If you start asking questions with 1 through 5, people start to tune out...fade out. Probably too many questions and too many variations. Probably fewer questions and just more casual: was the person weak, adequate, or strong? That is all that is really meaningful on a team." The view that the questionnaire itself was too lengthy was explained, also: "The first one [deal], I think five people answered every one [question]. .....it was too long a process. And then I cut it down; I think I answered 6 or 7 which were the most important. Some of them didn't apply for what some people were doing but that was my one feeling....that it was a little long. But it was very good."

Concordant with Hitchcock (1997), peer review was not seen as an appropriate measure for bonuses. There was general wariness in thinking that evaluation data were actually used in determining a monetary award: "The role of a good manager is to figure out what motivates the people that he manages, and in some cases it is not necessarily monetary. So yeah, the bonuses were fine, but I know that the teams I worked on generated a lot of money for the company, and I believe bonuses were based on revenue, not personal qualities or anything."

What impact (if any) did the use of the technology have on the overall value of the peer review process?

Planners, including myself, initially considered that the reason the peer review process was not as successful as anticipated was because users were finding the technology difficult to use. However, this was not the case as only the information systems executive who set up the system and the executive who had been charged with compiling the review data expressed negative reactions to its use. Reports were not generated as quickly or as easily as had been expected, and learning to format the reports so that data would be more understandable proved to be a difficult (but eventually mastered) learning experience.

To the contrary, individual users reported that the groupware was an enabler: "Yes, I liked the fact that you could log on and log off, $\log$ back and then submit it....I was using it all the time." Another said, "It was very user friendly once you got into it, so that was just fine." Yet another user said, "I thought the system was pretty easy to use even though I missed the training. It seemed to follow through. And it made sense." These technologically-literate individuals were quite at ease in understanding and using the system, and when asked if they would like to use the system in the future for such a process, responses were positive: "Yes, I would, definitely. Because it was very user friendly."

Consistent with earlier studies (Steeb \& Johnston, 1981; Gallupe \& McKeen, 1990), individuals believed the groupware was an appropriate fit for the peer review task. However, no one took the promise of confidentiality seriously: "Given the way I thought this stuff was being essentially used, I would almost be more comfortable writing something on paper and handing it to somebody. ...It may have been better if I knew exactly what was going to happen with this data. How was it going to be used or not used." Another interviewee said, "I think people took it with a grain of salt in terms of confidentiality. I think it depends on people, personalities, to keep this confidential or not." One interviewee said he told everyone he evaluated that he had given them high marks.

\section{Lessons Learned}

This paper described what happened when two innovations were introduced simultaneously. Results were mixed. Perhaps this is because while management was convinced of the value of peer review, individuals were skeptical. While top management was convinced of the value of groupware, implementers were not. To succeed, these two innovations-peer review and groupwareneeded to be seen by everyone as having an advantage over the way bonuses were traditionally awarded if they were to refreeze, to become part of the organizational culture.

Lesson learned: No good idea succeeds on its own merits; continual experimentation with peer review and the use of distributed groupware systems is needed. Keep the process itself as simple as possible.

The dual goal of the peer review process, to provide descriptors of how individuals were able to work as part of a team for bonus deliberations as well as confidential feedback given to reviewers was not seen by those interviewed as complementary outcomes and were not totally understood. In terms of value, individuals needed more assurance that their reviews would be taken seriously and used for their intended purposes. Only one of the individuals interviewed reported that she had had review feedback; and she had (mis)understood that the high marks she 


\section{Groupware-based Peer Review Process}

received from her colleagues would be used for promotion purposes, as opposed to bonus deliberations. Others reported that a perceived unofficial purpose, to remove specific individuals, dominated the process.

Lesson learned: State intended peer review objectives clearly; ensure everyone understand objectives; and followthrough on intentions.

Moreover, promises of confidentiality were not accepted at face value. Electronically signing reviews, meant to ensure review accountability, also meant that someone could know who said what. While this perceived lack of confidentiality was not cited as a major issue by individuals participating in the process, it may be seen as a potential stumbling block, thus inhibiting openness.

Lesson learned: Design the groupware system to ensure confidentiality.

\section{Concluding Comments}

The lessons learned here may initially seem obvious. However, we learn from our experiences and it is noteworthy to consider that this rather "ideal" site- an organization where individuals routinely work in teams and are technologically adept — had growing pains in establishing a technology supported peer review process. Given that teams are the building blocks of many of today's organizations, continued reports of strategies that assess individuals' teambuilding skills and reward good performance are valuable. Management will increasingly be faced with issues of how to reward a given individual for team outcomes, and we need to learn from what others have done.

A peer review process would seem to be compatible with the way work is done in a team-based, technology-driven organization, and this investigation shows that even innovations that appear to be a perfect fit require planning and have their own learning curve. Rogers' premise that the characteristics of an innovation impact its infusion into an organization is important here. Key to the activity is that the technology-supported peer review process be considered valuable and an improvement over the way things are done-in this case, a bonus deliberation. Perhaps more testing, or trialability, and experience in actually doing reviews, or observability, by both management and individual users will support the usefulness of these innovations. A shorter, more direct and truly anonymous questionnaire could reduce the complexity of the process, enhance validity, and provide more useful data. In short, to refreeze the peer review process in this organization, the value, compatibility, complexity, trialability, and observability of the two innovations investigated here must be continually addressed.

\section{Epilogue}

Refreezing Stage. The purpose of this section is to complete Lewin's paradigm — unfreezing, changing, and refreezing. Since the conclusion of this investigation, the organization studied has merged with a much larger organization. However, informal interviews with top management, confirmed by the focused interviews, suggest that the innovative culture of the smaller organization (the one studied) is taking precedence. Despite mixed reviews on the peer review process, management is reportedly committed to both peer review and continuing its use of groupware; they consider this investigation to be a pilot study or learning experience. The human resource executive is currently working to revise the peer evaluation instrument and evaluate the fit of the specific groupware tools used in data collection as a means to ensure more useful reports. In addition, information and operational training will be revised and more concerted efforts will be made to assure individuals that data will be used as planned.

In the short term, work will be done to ensure that the complexities of the peer review process are ironed out and another pilot test will ensure a more usable instrument and reporting process. In developing a blueprint for ensuring the success of both innovations, training will continue to play an important role in all stages of change, eventually changing the way "we do things around here."

\section{References}

Bikson, T. K. \& Eveland, J. D. (1996). Groupware implementation: Reinvention in the sociotechnical frame. Proceedings of the ACM Conference on Computer Supported Cooperative Work (pp. 428437). New York City: ACM.

Caouette, M. J. \& O'Connor, B. N. (1998). The impact of group support systems on corporate teams' stages of development. Journal of Organizational Computing and Electronic Commerce 8(1), 57-81.

Covey, S. (1996). Unstoppable teams. Executive Excellence, 13(7), 7-8.

Flynn, G. (1994). More companies use bonuses in place of traditional pay increases. Personnel Journal, 73(11), 16.

Frankfort-Nachmias, C. \& Nachmias, D. (1996). Research Methods in the Social Sciences ( $3^{\text {rd }}$ ed). New York: St. Martin's Press.

Gallupe, R. B. \& McKeen, J. (1990). Enhancing computer-mediated communications: An experimental study into the use of a decision support system for face-to-face versus remote meetings. Information and Management, 8, 1-13.

Gay, L.R. \& Diehl, P. L. (1992). Research methods for business and management. New York: Macmillan.

Hackman, J. R. (1991). Groups that work (and those that don't). San Francisco: Jossey-Bass.

Hitchcock, D. (1996). What are people doing around peer review? Journal for Quality and Participation, 19(7), 52-55.

Hsu, J. \& Lookwood, T. (1993) Collaborative computing. Byte, 28(3) 112-120. 
Kormanski, C., \& Mozenter, A. (1987). A new model of team building: A technology for today and tomorrow. In J. W. Pfeiffer (editor), The 1987 Annual: Developing Human Resources (pp. 255-267). San Diego: University Associates.

Lewin, K. (1972). Quasi-stationary social equilibrium and the problems of permanent change. In N. Margulies and A.P. Raia (editors) Organizational development: Values, process, and technology. New York: McGraw-Hill.

Martz, W. B.; Vogel, D. R.; \& Nunamaker, J. F., Jr. (1992). Electronic meeting systems: Results from the field. Decision Support Systems, 8(2), 141-158.

McClernon, T. \& Swanson, R. (1995). Team building: An experimental investigation of the effects of computer-based and facilitator-based interventions on work groups. Human Resource Development Quarterly 6(1), 39-58.

McLean, G. N. (1995). Partnering in human resource development. Human Resource Development Quarterly 6(1), 1-4.

Merriam, S. B. \& Simpson, E. L. (1995). A guide to research for educators and trainers of adults. Second edition. Malabar, FL: Krieger Publishing Company.

O’Connor, B. N. \& Bronner, M. (1995). Facilitating curriculum development: The role of electronic meeting systems. NABTE Review, (22), 5-9.

O’Hara-Devereaux, M. \& Johansen, R. GlobalWork: Bridging distance, culture \& time. San Francisco: Jossey-Bass, 1994.

The power of peer review (1994). Training and Development, 48(7), 38-41.

Rogers, E. M. (1983). Diffusion of innovations. Third edition. New York: Macmillan.
Rowden, R. W. (1995). The role of human resource development in successful small to mid-sized manufacturing businesses: A case study. Human Resource Development Quarterly 6(4), 355-373.

Smith, J. \& Vanecek, M. (1990). Dispersed group decision making using nonsimultaneous computer conferencing: A report of research. Journal of Management Science, 7(2), 71-92.

Steeb, R. \& Johnston, S. C. (1981). A computer-based interactive system for group decision making. IEEE Transactions on Systems, Man, and Cybernetics, 11(8), 544-552.

Talbott, S. P. (1994). Peer review drives compensation at Johnsonville. Personnel Journal, 73(10) 126-132.

Valacich, J. S.; Paranka D.; George, J. F., \& Nunamaker, J. F. (In press) Communication concurrency and the new media: A new dimension for media richness. Communication Research.

Vogel, D. R. (1990). Research on electronic meeting systems, in Research issues in information systems: An agenda for the 1990's, Jenkins, A. M.; Siegel, H. S.; Wojtkowski, W.; and Wojtkowski, G., eds. Dubuque, IA: Brown, p. 136.

Weisbord, M. R. (1987). Productive workplaces: Organizing and managing for dignity, meaning, and community. San Francisco: JosseyBass.

Work week: Evaluations (1995, May 2). The Wall Street Journal, p. $\mathrm{A}, 1: 5$.

Zigon, J. (1997). Team performance measurement: A process for creating team performance standards. Compensation and Benefits Review, 29(1), 38-47.

\section{Appendix A \\ Structured Telephone Interview Guide}

Focused Telephone Interview Guide

Thank you for taking the time to talk with me today. As you know, we are discussing the peer review process you went through last year. Your perspectives on both the peer review itself and your use of GroupSystems are needed. Using the following scale, please tell me the number that describes the degree to which you agree or disagree with the following statements. You will have an opportunity to explain your responses; the number is being used strictly as a way of getting you to begin discussing the statement.

$\begin{array}{lllll}5 & 4 & 3 & 2 & 1 \\ \begin{array}{c}\text { Totally } \\ \text { Agree }\end{array} & \text { Somewhat Agree } & \text { Neutral } & \begin{array}{c}\text { Somewhat } \\ \text { Disagree }\end{array} & \begin{array}{l}\text { Totally } \\ \text { Disagree }\end{array}\end{array}$

\section{Part I. Peer Review Process}

1. Approximately how many reviews did you complete?

2. I understand why and how the reviews took place.

Comments:

3. The questionnaire was an appropriate and easy to use evaluation instrument.

Comments:

4. I was comfortable in making informed ratings of my team members.

Comments: 
Groupware-based Peer Review Process

5. I was comfortable having team members rate my own performance.

Comments:

6. I have no doubts that data from reviews will be kept confidential.

Comments:

7. I personally believe that a peer review process is important.

Comments:

Is there anything else you'd like to talk about with regard to the peer review process?

\section{Part II. Use of GroupSystems Technology}

Using the following scale, please tell me the number that describes the degree to which you agree or disagree with the following statements. Again, you will have an opportunity to explain your responses; the number is being used strictly as a way of helping you begin discussing the statement.

$\begin{array}{lllll}5 & 4 & 3 & 2 & 1 \\ \begin{array}{c}\text { Totally } \\ \text { Agree }\end{array} & \text { Somewhat Agree } & \text { Neutral } & \begin{array}{c}\text { Somewhat } \\ \text { Disagree }\end{array} & \begin{array}{l}\text { Totally } \\ \text { Disagree }\end{array}\end{array}$

1. Approximately how much time did you spend completing each review?

2. I routinely use computers in my daily work. minutes

Comments:

3. I have used GroupSystems previously for other tasks.

$\overline{12345}$

Comments:

4. The GroupSystems training enabled me to competently use the system to complete the reviews.

12345

Comments:

5. The system was an appropriate "fit" for the peer review process.

Comments:

6. The relative anonymity of the system allowed me to say things I

might not have said otherwise.

122345

Comments:

7. I am looking forward to using GroupSystems again.

123345

Comments:

Is there anything else you'd like to talk about with regard to the peer review process?

\section{Appendix B \\ Peer Review Introduction}

The objectives in implementing this peer review:

Self-development: feedback should be used as a means to behavioral change.

Measure teamwork effectiveness: feedback from one's peers on how a team leader or team member is performing, and the resulting modified behavior, can lead to increased productivity.

Development of a "partnership attitude."

Provide the Policy Committee with another tool to be used in evaluating an employee.

Guidelines:

Reviews must be signed. Any review without a signature will not be used.

Please rate each peer (team leader or team member) on the 5 point scale and add the critical event that supports your rank-

ing. Any ranking without the corresponding critical event will not be used. A critical event is a specific situation where the

skill/trait was observed by you.

Criticism should be constructive.

Review must be done on groupware.

Review on: (name of person being reviewed)

Your name:

\begin{tabular}{|c|c|c|c|c|c|}
\hline Rating scale & 5 & 4 & 3 & 2 & 1 \\
\hline & Exceptional & Superior & Consistently & Could & Improvement \\
\hline & All facets & Most facets & Capable & Improve & Required \\
\hline
\end{tabular}

